IRA-International Journal of Education \& Multidisciplinary Studies ISSN 2455-2526; Vol.05, Issue 02 (2016)

Pg. no. 94-113

Institute of Research Advances

http://research-advances.org/index.php/IJEMS

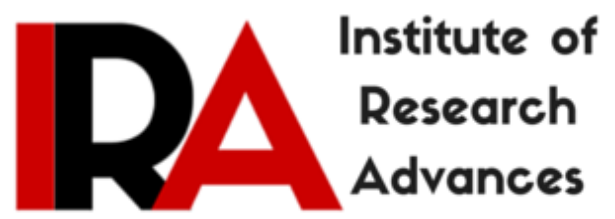

\title{
Translating the Three Kingdoms Cultural Attractions in Jingzhou and Xiangyang: Problems and Solutions
}

\author{
${ }^{1}$ Jingjing Zeng $\boldsymbol{\&}^{2}$ Chuanmao Tian ${ }^{*}$ \\ School of Foreign Studies, Yangtze University, \\ Hubei, 434023 P. R. China.
}

Type of Review: Peer Reviewed.

DOI: http://dx.doi.org/10.21013/jems.v5.n2.p5

*Corresponding author.

\section{How to cite this paper:}

Zeng, J., \& Tian, C. (2016). Translating the Three Kingdoms Cultural Attractions in Jingzhou and Xiangyang: Problems and Solutions. IRA International Journal of Education and Multidisciplinary Studies (ISSN 2455-2526), 5(2), 94-113.

doi:http://dx.doi.org/10.21013/jems.v5.n2.p5

(C) Institute of Research Advances

(c) EY-NC

This work is licensed under a Creative Commons Attribution-Non Commercial 4.0 International License subject to proper citation to the publication source of the work.

Disclaimer: The scholarly papers as reviewed and published by the Institute of Research Advances (IRA) are the views and opinions of their respective authors and are not the views or opinions of the IRA. The IRA disclaims of any harm or loss caused due to the published content to any party. 


\begin{abstract}
With the rapid development of globalization, the trans-cultural communication has become more and more frequent. Tourism has become more popular with people as one of the ways in trans-cultural communication. In travelling, people cannot only spread their own culture, but also study other cultures. However, it is the transnational tourism that makes all kinds of languages encounter and gives rise to the differences among these languages. Thus, translation is one important way to solve this problem. As one of the ways in trans-cultural communication, tourism translation has its vital function. Therefore, a number of researches have been done by many famous experts and scholars. However, my literature search indicates that the researches about tourism translation abroad are relatively few, even though there are many at home. As far as China as a whole is concerned, Hubei Province boasts rich and abundant cultural relics. The cultural resources of Hubei Province are heterogeneous yet diversified, including Chu culture, Three Kingdoms culture, "Red Culture" related to the revolution under the leadership of the Communist Party of China, and so on. Most cities, towns and villages in Hubei Province are endowed with these cultural resources among which the Three Kingdoms culture is one of the main cultural resources in the province. The Three Kingdoms cultural tourism is concentrated in the cities of Jingzhou and Xiangyang where there are currently many problems with the translations of the scenic areas or spots. This paper firstly discusses the significant role of the Three Kingdoms culture in the construction and development of cultural tourism in Hubei Province. Then, referring to the present translation situation in the Three Kingdoms cultural attractions in Jingzhou City and Xiangyang City, it analyzes the problems existing in the Three Kingdoms cultural tourism translation in Hubei Province. According to the analysis, it puts forward the countermeasures, strategies, methods and principles to solve the problems.
\end{abstract}

Keywords: Jingzhou; Xiangyang; Three Kingdoms culture; tourism; translation; problems; solutions

\title{
1. Introduction
}

\subsection{Background of the study}

Many famous scholars in China have so far studied tourism translation from many aspects, including definition of tourism translation, regional tourism translation, research on tourism translation from different theoretical perspectives, and so on. From these studies, we can see that tourism translation is not only a work for tourists, but also a great contribution to the tourism development of our country. Thus, the translators have to shoulder more responsibility for their work. To my knowledge, the scholars abroad have done few researches in this regard. But the relevant theories formulated by them are useful for tourism translation.

As far as the whole country of China is concerned, Hubei Province boasts rich and abundant cultural relics. The cultural resources of Hubei Province are heterogeneous yet diversified, including Chu culture, Three Kingdoms culture, Taoist culture, revolutionary "Red Culture", and so on, among which the Three Kingdoms culture is one of the main cultural resources in the province. The Three Kingdoms cultural tourism is concentrated in the cities of Jingzhou, Xiangyang, Chibi, Dangyang, and so on. In theses places, various kinds of textual materials, including publicity 
banners and posters, public signs, scenic spots' names and introductions, service and entertainment facilities' names and introductions, and tourism products' names and introductions are provided with few English translations. This situation is not conducive to putting the Three Kingdoms cultural tourism on the international market. For example, some spots of the Gulongzhong scenic area in Xiangyang City are supplied with English translations and some other spots there are provided only with Japanese translations. In Jingzhou City, the major Three Kingdoms attractions including Guandi Temple and Guanyu Temple are provided only with the English translation of their introductions. The scenic spots in Chibi and Dangyang see very few English translations for texts in Chinese. As for the translations available in the cities, there are many thorny problems that need to be solved.

\subsection{Research questions and methods}

Based on the analysis of the present situations of the translation problems in the translation of publicity materials in Xiangyang and Jingzhou, this paper mainly focuses on putting forward some constructive suggestions on the existing problems in the Three Kingdoms cultural scenic spots so as to introduce the Three Kingdoms culture to the outside world. Therefore, the research questions of this study are formulated as follows:

i)What's the current situation of the translation of Three Kingdoms cultural attractions in Jingzhou and Xiangyang?

ii)What are the problems concerning the translation of these cultural attractions?

iii)What solutions to these problems can be found?

In order to find the answers, the author of this paper has made some surveys and analyses about the tourism translation in both cities. She has even been to the scenic spots by herself to collect data about the translation of Three Kingdoms cultural destinations there. Then, through field observation and analysis of the existing translations, she has put forward some methods and principles to solve the existing problems and improve the translation quality in the scenic spots.

\subsection{Structure of the thesis}

This thesis falls into five chapters. Chapter One is the introduction of the paper, including the background and research questions and methods of the study. Chapter Two is the literature review with the definition of tourism translation, the regional tourism translation and the research perspectives of tourism translation. Chapter Three is to discuss the situations and the existing problems of the translation of the Three Kingdoms cultural attractions in Jingzhou and Xiangyang.

Chapter Four introduces the methods, principles and solutions to improve the translation quality in the scenic spots. The author will carefully analyze the problems existing in the scenic spots and then offer the proper methods to solve the problems. Chapter Five is the conclusion of the thesis.

\section{Literature Review}

With the development of globalization, the trans-cultural communication among all the countries has become more and more frequent. Tourism has been more and more popular with people as one of the ways in trans-cultural communication. In travelling, people cannot only spread the culture of 
their own countries, but also study the culture of other countries. However, it is the transnational tourism that makes all kinds of languages encounter and gives rise to the differences among these languages. Thus, translation is one important way to solve this problem. As one of the ways in trans-cultural communication, tourism translation has its vital function. Therefore, a number of researches have been done by many famous experts and scholars. However, my survey indicates that the researches about tourism translation abroad are few, even though there are many at home. According to this, I have made some conclusions about tourism translation researches made by the scholars at home.

\subsection{Definition of tourism translation}

Professor Chen Gang (2004:59) has formulated a definition for tourism translation. He points out that tourism translation should be seen as a kind of translation which is done for travel activities, travel profession and travel business. It belongs to professional translation. Generally speaking, tourism translation is a communicating activity which happens between different languages, societies, times, cultures and thought patterns. Compared with other types of translation, it is more direct, more remarkable, more typical and more comprehensive in trans-cultural and inter-lingual communicating characteristics.

\subsection{Regional tourism translation}

Regional tourism translation is one kind of translation which translates the texts, slogans and names in the tourist destinations of a certain region from one language to another. In China, translation of scenery spots tends to be done between Chinese and English. And in a few regions such as Guangdong and Xinjiang, the translating work happens between Chinese, Japanese and Korean.

\subsubsection{Tourism translation in Guangdong Province}

In the article "On Tourism Translation in Guangdong Province”, Professor Jin Huikang (2003:23) has discussed the tourism translation problems in Guangdong Province in public signs of daily life, traditional cultural words, transportation words, business words and entertainment facility-related words. As far as the public signs of daily life are concerned, his discussion covers several aspects, including signs of place names, signs in modern residential areas and signs in public amenities. He points out that, in translating place names, we should strictly follow the policies and laws issued by our government using the Chinese pinyin method. Only in this way, can the translation work achieve standardization and be conductive to international communication in translating public signs in modern residential areas. He argues that we should uniformly use "quarter" to translate such words as “小区”, “花园”, “新村”, “新城”, “苑” and “园”. In translating the signs on public amenities, we should follow international conventions instead of translating them at will. In other aspects, such as translation of cultural words, Professor Jin (2003:24) has also given in-depth research findings according to his research data and his own understanding.

\subsubsection{Tourism translation in Xinjiang Autonomous Region}

In his article "The Present Situation of Regional and Cultural Tourism Translation in Xinjiang and Normalization Research", Professor He Jizong (2006:42) has discussed regional and cultural tourism translation in Xinjiang from three aspects. The first one is about the regional and cultural characteristics in Xinjiang. The second one is about the present situation of regional and cultural 
tourism translation in Xinjiang. In this aspect, he has given good solutions to the existing problems, such as inconsistency in the translation of the same name in scenic spots, explanatory translation with no attention paid to the sound in tourism translation, misunderstanding of source language cultural information and overloaded translation. In addition, in the aspect of giving suggestions in normalizing the regional and cultural tourism translation in Xinjiang, he points out that, first of all, we should implement the standardized administration in the translation market. (ibid.:44) Then, tourism translation is not only one kind of cultural translation, but also diplomatic translation and foreign publicity. Thus, translators should not only have proficient translating skills, but also good professional ethics. Finally, translators should do the translation work according to the National Translation Service Standard.

\subsection{Theoretical perspectives on tourism translation}

In the article "Application of 'Perspective' in Tourism Translation", Tian Hua (2001:67), a scholar of Liaoning University of Engineering Technology University, points out that the perspective reflects the angle and attitude of people to look at this world. This is a concept involving the observer, the observed target and the way of observation and reflecting the surface structure of language. In tourism translation, the translator should choose words in correspondence with the perspective of the original text. Sometimes, the descriptive perspective should be shifted from objective perspective in English to subjective perspective in Chinese. As for the perspective of text, in translating English into Chinese, we can convert the focal-point perspective of the original text into the discrete-point perspective and in translation from Chinese to English, we should set up a controlling perspective to guide the whole text. In tourism translation, different researching perspectives cause the different understandings of the source text. The following are the research perspectives advocated by different scholars in tourism translation.

\subsubsection{The translation variation theory and tourism translation}

In the article "The Translation Variation Theory-oriented Tourism Translation Strategies from Chinese to English", Zhang Yange (2007:67) points out that the tourism translation from Chinese to English is not only one kind of cultural translation, but also a kind of trans-cultural communicating activity. Due to the great cultural differences between Eastern countries and Western countries, especially the different characteristics between Chinese and English in tourism texts, it is difficult for us to do the translation from Chinese to English in tourism translation. The formulation of the theory of translation variation (bianyi, 变译) by Professor Huang Zhonglian (2002) frees us from the traditional translation concept of full translation. The comprehensive application of different methods of editing-translating (i.e. transediting) in the translation variation theory provides tourism translation from Chinese to English with an effective method. The article gives the reason why we should use methods of translation variation in the process of translating tourism texts and discusses how we can use them from two aspects. One aspect is about the difference between English and Chinese tourism texts and the other is about the strategies for tourism translation from Chinese to English under the guidance of the translation variation theory. And he puts emphasis on the second aspect, putting forward the method of word-order adjustment and transediting, the method of summary and transediting, the method of translatorial narration and transediting, and so on. These methods have effectively solved some problems that translators often encounter in translating tourism texts. 


\subsubsection{The strategy of foreignization in tourism translation}

In the article "The Translation Strategy of Foreignization in Trans-cultural Tourism Translation", Zheng Lijun (2009:89) points out that domestication and foreignization are two different translation strategies and both of them have their own advantages. It is easy for readers to understand the original text by using domestication while using foreignization can, to the largest degree, preserve the characteristics of the original text. The translator will choose different translation strategies according to different texts, different translating purposes and different readers. As far as I'm concerned, the purpose of translating tourism texts is to introduce Chinese culture to foreigners and attract more foreign visitors. Therefore, foreignization is the best translation strategy for tourism texts. The first part of this article points out that the responsibility of tourism translation is to publicize local culture. The British scholar Peter Newmark believes that tourism translation should introduce to target readers not only the tourism information contained in the original text, but also the tourism culture related to scenic spots. Zhuang Enping and Zhang Qi (2007:52) put forward a similar view that the translation strategy of foreignization is a bridge strengthening successful trans-cultural communication. In the second part, Zheng Lijun studies the application of foreignization in tourism translation from the significance of using foreignization in tourism translation. In the third section of this part, the author comes up with several methods which can be used in translating tourism text, including transliteration with explanatory note, integrating transliteration with free translation, free translation with explanatory note, and so on.

\subsubsection{Readability in tourism translation}

In the article "Research on Readability in the Tourism Translation from English to Chinese", Yang Hongying and Huang Wenying (2009:68) point out that the translated text with high readability will attract more readers and the communicating value of the translated text can be rapidly, widely and comprehensively presented. On the contrary, if the readability of the text is low, the interest and motion of readers will be unfavorably influenced and it will even let readers give up reading. Then, the communicating value of the translated text will be restricted or cannot be achieved. Therefore, translators should not ignore the problem that it is important for us to try our best to improve and enhance the readability of the translated text. To handle this problem, Yang Hongying and Huang Wenying have done a careful survey. They asked 67 tourists questions about tourism translation and worked out four reasons for the low readability of tourism translation. The reasons are the mispronunciation of tour guides, the improper words and expressions used by tour guides in their introduction and explanation of the scenic spots, the misleading translation of the public signs in the scenic spots and cultural difference. These are merely part of the reasons for the low readability of tourism translation, which have given great inconvenience to the tourists. From this we can see that the problem of readability should be given enough attention in the process of translating tourism texts.

\subsubsection{Rhetorical deviation and adaptive aesthetic truth transfer in tourism translation}

Yang Jingsong and Zeng Wenxiong (2008:46) have pointed out that tourism translation is not only to convey meaning, but also to explain and develop something at the level of culture. Thus, in the practice of tourism translation, sometimes we should break the language rule of the source language so that we can comply with the trend of language and cultural habits of the target language. They introduce the relationship between the rhetorical deviation operation and the adaptive translation 
aesthetics truth transfer and their application in tourism translation. The authors focus on introducing the use of various kinds of rhetorical deviation operation and adaptive translation aesthetics truth transfer in tourism translation, including adding operation and adaptive translation aesthetics truth transfer, omitting operation and adaptive translation aesthetics truth transfer, substituting operation and adaptive translation aesthetics truth transfer, and transposition operation and adaptive translation aesthetics truth transfer. These four aspects make readers have full understanding of the significance of rhetorical deviation operation and the adaptive aesthetic truth transfer in the process of tourism translation.

\subsection{Summary}

The three aspects introduced above are my summary of the previous research on tourism translation at home. Certainly there are many more research perspectives of tourism translation, but space limits do not allow me to list them all here. However, from the above introduction, it is not difficult for us to find that all of these scholars are trying their best to follow the three translating principles, namely, faithfulness, expressiveness and elegance, even though their research perspectives are different. In the three principles, faithfulness is the most important one. In research on regional tourism translation, the translators should comprehensively apply all research perspectives and make every possible effort to make a comprehensive, in-depth and exact analysis of the source text before they begin to translate it.

The task of this paper is to analyze the situation and existing problems of the translation in Three Kingdoms cultural attractions in Jingzhou and Xiangyang. Therefore, based on the above theories on tourism translation, the author of this paper will put forward effective solutions to the problems so as to promote the development of the tourism industry in Jingzhou and Xiangyang.

\section{The Current Situation and Problems of the Translation in Three Kingdoms Cultural Attractions in Jingzhou and Xiangyang}

Hubei is a province with rich tourism resources and cultures. The cultural tourism resources of Hubei Province are heterogeneous yet diversified, including Chu culture, Three Kingdoms culture, "Red Culture" related to the revolution under the leadership of the Communist Party of China, and so on. The Three Kingdoms cultural tourism plays an important role in the tourism industry in the province. The major Three Kingdoms cultural tourism cities in Hubei include Jingzhou, Xiangyang, Chibi, Dangyang, and so on.

In theses cities, all kinds of textual materials, including publicity banners and slogans, public signs, scenic spots' names and introductions, service and entertainment facilities' names and introductions, and tourism products' names and introductions are provided with few English translations. This condition does harm to helping the Three Kingdoms cultural tourism to win the international market. For example, only some spots of the Gulongzhong scenic area in Xiangyang City are supplied with English translations and some other spots there are provided only with Japanese translations. In Jingzhou City, the major Three Kingdoms cultural attractions including Guandi Temple and Guanyu Temple have not so far offered an English version for all the textual materials except their introductions. The scenic spots in Chibi and Dangyang witness very few English translations for texts in Chinese. As for the translations available in the cities, there are many serious problems. 


\subsection{Current situation of the translation in the scenic spots}

\subsubsection{Texts with no translation}

In order to present the authentic materials, the author of this paper has been to the Three Kingdoms cultural scenic spots to collect data. In Jingzhou, there are a few Three Kingdoms cultural attractions, including Guandi Temple, Guanyu Temple, Zhangfei Dantu Hall, and so on. Only Guandi Temple offers a few English translations. However, the allusion-related names in the temple are not provided with their English translation. In Guanyu Temple and Zhangfei Dantu Hall, there is no translation at all. In Xiangyang, there are more translations in the scenic spots than in Jingzhou but many entertainment facilities there do not offer any translation either. It is not convenient for foreign tourists to visit the scenic spots.

\subsubsection{Translated texts}

In Jingzhou, many textual materials of the attractions are only in Chinese and only a few in both Chinese and English. In Xiangyang, the situation is complex. Some scenic spots offer the English translation of Chinese texts; some others provide both English and Japanese translation. The nonstandard translation not only makes the tourists confused, but also impedes the smooth development of the Three Kingdoms cultural tourism industry in both cities.

\subsection{Problems concerning the translation in the scenic spots}

\subsubsection{Problems in source texts}

In the Gulongzhong scenic spot of Xiangyang, there exist a few mistakes or unsatisfactory places in the Chinese name of the scenic spots, the introduction of the scenic spots, punctuation marks, and so on. For example, “武侯祠” is written as “武候祠”. In the first sentence of the introduction of Wuhou Hall, the character “年” should be put inside the brackets but the original introduction is “始 建于晋朝（公约元 361）年”. In the introduction of Baguazhen, the last sentence “我们按照世传 的诸葛亮八阵恢复了八卦阵认供游客探索八阵奥妙, 领略孔明智慧” has a careless blunder that “以供” is mistakenly written as “认供”. There is no punctuation mark in the whole passage of the introduction of Liujiao Well. The tourists have to try their best to guess its meaning by themselves. This situation seriously prevents tourists from knowing Liujiao Well quickly and effectively.

\subsubsection{Translation problems}

3.2.2.1 Publicity banners and public signs in the scenic spots

According to the Xiangfan Journal, it was reported that on July 1, 2009, in the AAAA level scenic spots of the city there are a lot of mistakes or errors in the English slogans. For example, in the large billboard, the word "Welcome" in the sentence "Welcome guests far and near and meet heroes all around" is carelessly written as "Welconme". The word "maintain" in the sentence "Obey social morality and maintain public order" is carelessly written as "maintaion". "Xiangfan" is wrongly spelt as "Xinangfan". The similar mistakes or errors also exist in the other scenic spots. For example, in Migong Hall, “小心滑倒” is carelessly mis-translated into "Watch Out Slippeng-Ftoor”. And “小心触电” is carelessly and wrongly translated into "Danger telectric shock”.

Furthermore, there are many other mistakes which make people puzzled. In the introduction of Migong Hall, the translator might have intended to use "sacred" to express the meaning of holiness. As a result, the translator mistakenly used the word "scared". The original phrase turns into the "scared place" instead of "sacred place". In Gulongzhong, the word "tomb" in the English version 
of “襄王陵”" refers to the burial ground for common people. If it is a duke or emperor, the word should be "mausoleum". It seems that it is proper to translate “襄王陵” into "Mausoleum of Duke Xiangyang”. In the introduction of the city museum, “楚人” has two kinds of translation: “Che people" and "Chu people". This will easily make people think that the people are from two different countries.

\subsubsection{Names of the scenic spots}

The names of scenic spots are of public signs. Their translation has been mentioned in the section above. Now, the author of this paper will discuss them because of their great importance. In Xiangyang, there are many scenic spots in the Gulongzhong scenic area. Most scenic-spot names have been translated there. The existing problems are as follows:

i) Inconsistency in the translation of the same scenic spot

For instance, “老龙洞” is sometimes translated into Old Dragon Hole and sometimes into Early Spring of Dragon's Cave. One translation of “三顾堂” is Three Visits Hall and the other is Tri-visit Hall.

ii) Spelling mistakes

For example, in “草庐亭” (Thatched Hut Pavillion) and “腾龙阁”(The Flying-dragon Pavillion), both “亭” and “阁” are translated into "pavilion” and both of them are mistakenly written as “pavillion”. The word “temple” (“祠”) in “Memorial Tempel of Lord Wu” (“武侯祠”) is misspelt as "temple".

iii) Inconsistent and nonstandard spelling of proper nouns

For instance, “隆中” has two Chinese pinyin versions: Long Zhong and LongZhong and the normal spelling is Longzhong. “诸葛亮” also has two Chinese pinyin versions: ZhuGeLiang and ZhuGe liang and the normal spelling is Zhuge Liang.

iv) Inconsistency in translation method

For example, the English version of “腾龙阁” uses the definite article "the" while the English version of “草庐亭” does not use it. Both “腾龙” in “腾龙阁” and “卧龙” in “卧龙深处”are noun phrases. “腾龙” is translated into a compound noun, namely, “flying-dragon" while “卧龙” is translated into two words, namely, “sleeping dragon”. The translating method of “卧龙” in “卧龙深 处” is different from that of “卧龙” in “卧龙岗”. The former is a free translation and the latter is a transliteration ("wolong").

v) Inappropriate writing form

For instance, in “八卦阵” (The Eight Diagrams Game), the first part of the translation “The Eight” is in italics while the latter part isn't. The Chinese and English names “孔明茶室” and “冷兵器展” are written in the same billboard without putting any dividing marker in between. The Chinese names are easy to distinguish but the English translations of the names (Kongming Teahouse Exhibition Hall for Cold Weapon) may cause misunderstanding.

3.2.2.3 Introductions to the scenic spots

In Gulongzhong of Xiangyang, some scenic spots have English translations, including Memorial Tempel of Lord Wu, Zhuge Grass Pavilion and Three Visits Hall while in Jingzhou, only Guandi Temple and Guangong Museum have the English version of their introduction. The following is the Chinese introduction to Jingzhou Guandi Temple and the English translation. The author of this paper uses it as an example to classify the translating problems. The source text goes as follows: 
州关帝庙简介

关帝庙位于三国历史名城荆州古城老南门内, 原为三国时期关羽镇守荆州时的官 邸，始建于明洪武二十九年，修复于公元一九八七年，现有仪门、正殿、三义殿、陈 列楼等仿古建筑。

正殿及三义殿内供有关羽夜读春秋、桃园三结义等雕像，以及绘制精美、气势恢 弘的三国故事壁画, 陈列楼内陈列赤兔马雕塑以及关公刀、石马槽等文物, 院内有粗 壮挺拔、古老苍劲的明万历年间栽植的银杏树。

关帝庙整个建筑殿宇起伏, 廊阁环绕、古朴典雅、错落有致, 独具荆州三国历史 文化之特色, 实乃广大海内外喜爱三国文化, 崇尚关公精神的人们观光朝圣的一处胜 地。

The following is the target text:

\section{A BRIEF INTRODUCTION TO JINGZHOU QUANDI TEMPLE}

JINGZHOU GUAN DI TEMNPLE is located inside the old southern gate of Jingzhou City,a famous historic city with the historic culture of Three Kingdoms.It was originally built during the twenty-ninth year of Hong Wu in Ming Dynasty and it was used by the viceroy, Guan $\mathrm{Yu}$ (Guan Gong) for official residence when he was guarding Jingzhou during the times of Three Kingdoms.In memory of Guan Gong it then became a temple. It was rebuilt in 1987.Now it contains imitation of ancient buildings like Gate of Ceremonies,Main Palace,SANYI Palace,Exhibition Hall,etc.

The Main Palace contains a statue vividly describes Guan Yu reading The Spring and Autumn Annals at night.At SANYI Palace, a group of statues showing the ancient heros LIU BEI,GUAN YU and ZHANG FEI swearing brothers are on display,which known as "TAO YUAN SAN JIE YI", as well as elegant frescoes about the stories in the times of Three Kingdoms are on the walls.In the Exhibition Hall,some rare and valuable historical relics are on display such as Statue of "CHI TU Horse",Guan Gong's Broadsword, Stone Manger, etc.The ancient strong,hardy,tall and straight dioecian gingkoes which were planted in the year of Wan Li in Ming Dynasty stand in the courtyard of the temple.

JINGZHOU GUAN DI TEMPLE is dotted with palaces and temples rising and falling, surrounded by galleries and pavilions.It is full of clas-

sic elegant architectural styles,features and unique historic culture of Three Kingdoms. It is really a famous scenic spot for tourists both at home and abroad to appreciate the historic culture of Three Kingdons and go on a pilgimage to Guan Gong.

In the following part we will discuss the problems in the above translation and then offer the solutions to them.

i) Poor quality of text layout

The target text is carelessly designed and printed in terms of punctuation marks. A close look at the target text shows that there is no space left in the places of many commas, periods and other punctuations marks, thus giving target readers the impression that the words of 
the text are crowded together and that the text producer wants to save paper and money. As a result the layout is lack of generous and elegant appearance. For example, let's see the underlined places in the first part of the target text:

JINGZHOU GUAN DI TEMPLE is located inside the old southern gate of Jingzhou City,a famous historic city with the historic culture of Three Kingdoms.It was originally built during the twenty-ninth year of Hong Wu in Ming Dynasty and it was used by the viceroy, Guan $\mathrm{Yu}(\mathrm{Guan}$ Gong) for official residence...

Moreover, the word "classic" is split into two parts in the middle of the paper as illustrated below:

...It is full of clas-

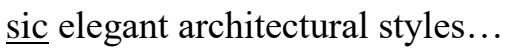

We can see that "classic" (a complete word) is split into two parts as "clas" and "sic" with the former in a line and the latter in the next. However, "clas" does not reach the very end of the right-hand side of the paper and there is much room for accommodating "sic", so this kind of splitting is unreasonable. Clearly, it is a kind of the negligence of the typesetters. These problems greatly give some negative impacts on the appearance of the target text layout.

ii) Improper use of proper nouns

Use of proper nouns in the target text is inconsistent. One problem is that the spelling is not consistent. For example, "关羽" is sometimes spelled as GUAN YU, and sometimes as Guan Yu. Another problem is that use of the Chinese pinyin method in the target text does not accord with the current translation norms in China. For example, "三义" is transliterated as SANYI in the target text by using capital letters. However, it is commonly translated as Sanyi or San Yi according to the standard norm.

iii) Inappropriate use of words

Use of some words in the target text seems inappropriate. For example,

Now it contains imitation of ancient buildings like Gate of Ceremonies, Main Palace,

SANYI Palace, Exhibition Hall, etc.

In the example above the word "like" should be replaced by "such as" in accordance with the prescriptive grammar of the English language.

iv) Syntactic errors

Use of English in the target text does not conform to the syntactic norms of English grammar in a few places. Please look at the following example:

The Main Palace contains a statue vividly describes Guan Yu reading The Spring and Atumn Annals at night. At SANYI Palace, a group of statues showing the ancient heros LIU BEI,GUAN YU and ZHANG FEI swearing brothers are on display, which known as "TAO YUAN SAN JIE YI", as well as elegant frescoes about the stories in the 
times of Three Kingdoms are on the walls.

The underlined part in the example "contains a statue vividly describes" should be corrected to be "contains a statue which vividly describes" or "contains a statue vividly describing". The attributive clause "which known as" should be corrected to be "which is known as". The prepositional phrase "as well as elegant frescoes" could be replaced by "and there are also elegant frescoes".

\section{v) Misunderstanding}

The unidiomatic expression and mistranslation in the target text are obviously because of the translator's misunderstanding of the source text. For example, the translation "in the year of Wan Li in Ming Dynasty” of “明万历年间” results from the misunderstanding of the original expression. The reign of Emperor Wanli of the Ming Dynasty lasted 47 years (1573-1620 but not one year. However, the above translation implies that his reign lasted only one year. The source text implies that the temple was built in a certain year of Emperor Wanli's reign. Therefore, "in the year of Wan Li in Ming Dynasty" may be improved as "in the reign of Emperor Wanli in the Ming Dynasty". Another example of this kind lies in the translation of the first sentence of the third paragraph:

JINGZHOU GUAN DI TEMPLE is dotted with palaces and temples rising and falling, surrounded by galleries and pavilions.

“殿宇” of “整个建筑殿宇起伏” in the source text clearly refers to various buildings in Guandi Temple, but the corresponding target text is "palaces and temples", which is illogical and misleading in that Guandi Temple has many temples inside it. Translating of "起伏" into "rising and falling" seems too mechanical and literal. The nature of this mistranslation is like that of "殿宇". Here, “关帝庙整个建筑殿宇起伏” may be translated into “Jingzhou Guandi Temple contains rich forms of undulating buildings".

vi) Mistranslation of culture-specific expressions

The original text has some words and expressions with rich cultural connotations, such as “洪武”, “春秋”, “桃园三结义”, “三义殿”, “赤兔马” and so on. The translation of “春秋” into “Spring and Autumn Annals" is a free one and it is intelligible. The transliteration of “桃园三结义” as “TAO YUAN SAN JIE YI" is also understandable to target readers due to the strong implication of the context. The other transliterations of the cultural words and expressions in the source text are completely unintelligible to English readers, such as "Hong Wu", "SANYI Palace", "CHI TU Horse", and so on. Some translation methods may be employed to deal with the rendering of these cultural expressions. For example, we might use amplification and annotation to translate “洪武二 十九年” into “the twenty-ninth year of the reign of Emperor Hongwu (1397)" so that foreign tourists can understand the specific meaning of “洪武” and “洪武二十九年”. “三义” of “三义 殿” refers to the three sworn brothers who are Liu Bei, Guan Yu, and Zhang Fei. A free translation of “三义殿” will be “Three Sworn Brothers Palace”, and it seems to convey the original meaning directly with no need of offering any explanation or note, but its drawback is to erase the Chinese characteristic of the proper names in the source text.“赤兔马” can also be rendered by literal translation as "Red-hare Horse" which may be misleading to foreigners in that they may think that the horse is like a red hare. Actually, the original expression implies that the head of the horse is 
like that of a hare, so a note is necessary to clarify its implication. The translation of “三国” into "Three Kingdoms" is inaccurate and the definite article "the" should be put before it.

In addition, there are problems of wrong word spelling and character dropping. For instance, in the translation of the introduction in the Gulongzhong scenic area, the word "renowned" is carelessly written as "reknowned". In the translation of the brief introduction to Zhuge Grass Pavilion, the spelling of Zhuge Liang should have used capital letters but it is spelled as zhuge liang. Because of the long-term suffering of wind and rain, many words in the translation have dropped down from the brief introduction board of Guangong Museum in Jingzhou. For example, the letter " $t$ " drops from the word "dynasty" which turns into dynas $y$. The letter "b" falls off from the word "above" which turns into a ove. There are 14 places like this in the introduction.

3.2.2.4 Service and entertainment facilities' names and introductions

In Gulongzhong of Xiangyang, there are problems with the translation of the name and introduction of service and entertainment facilities, including word spelling, punctuation mark, translation accuracy, and so on. For example, the English word of “茶” in “卧龙茶社” is “tea” but it is mistakenly written as "ten". In the translated introduction of Longzhong Chute, the words "and" and "reliable" are written together as "andreliable". The word "recreation" is mistakenly written as "creation". In this brief introduction, many places use comma instead of full stop, as in "The length of up cableway is 400 metres, The length of down cableway is 900 meters, The difference of the height.". It is inaccurate to translate “高差” into "height difference”. It is proper to translate it into "difference of elevation" or "elevation difference".

\subsubsection{Translation blanks}

In Hubei Province, only the Three Kingdoms cultural scenic spots in Xiangyang have relatively complete English translations. In other cities, the English translation of the scenic spots is hardly seen. The cultural tourism translation does not only include rendering of textual materials and symbolic resources in scenic areas, such as scenic-spot publicity slogans, public signs and various kinds of proper names and introductions, but also that of various kinds of derivatives, such as tourist souvenirs, relevant cultural classics, local sceneries and fables, relevant scholarly research literatures, and so on. In terms of tourism translation concerning the scenic spots of Three Kingdoms culture in Jingzhou and Xiangyang, the tremendous translation project will be completed with the joint efforts of individuals and government departments who are willing to devote themselves to the publicity of the Three Kingdoms culture to foreign tourists.

\section{Solutions to Improving the Translation Quality of the Scenic Spots}

\subsection{Translation methods and principles}

\subsubsection{Translation methods}

The concrete application of translation methods in cultural tourism should focus on the cultural charm of the original language and communicative effects. The translators should also take a dialectical attitude to translation methods. In other words, they are supposed to use methods flexibly to achieve the translation purpose. The following methods are summarized according to the translation of the textual materials available in both cities.

\subsubsection{Transliteration}

This is a method using the phonetic resources of the target language to imitate the phonetic features 
of the souce text. For example, the Chinese pinyin method, a special type of transliteration, can be adopted to translate “赤兔” of “赤兔马” So, the translation of “赤兔马” is Chitu Horse. Transliteration can give people a strong feeling of foreignization and the reason may be that transliteration can retain the so-called signifier by Ferdinand de Saussure, namely, the sound image of the source language, which can create an exotic flavor in the target language-culture. However, transliteration is unsatisfactory in reproduction of the original meaning, especially cultural meaning. If it is used together with paraphrase or explanation, it can be a good method in tourism translation.

\subsubsection{Literal translation}

This is a method which represents the literal meaning of the original text. Again, Let's take “赤兔马”. If it is translated literally, the translation will be "Red-hare Horse”. Compared with transliteration, literal translation has a strength that lies in its stronger capacity of semantic expression as well as its preservation of the original image. Generally speaking, Chinese readers' understanding of “赤兔马” is similar to English readers' understanding of "Red-hare Horse”. Whether they are faced with the real object or not, they must know that the shape and color of this horse is like a red rabbit. If he is careful enough, the tourist may know that "Chitu" refers to the fact that the head of the horse is like that of a red hare when he or she faces the model of the real object. The literal translation of "Red-hare Horse" not only keeps the cultural characteristics of the original language, but also achieves nearly the same communicative effect as the original text.

\subsubsection{Free translation}

This is a method which does not blindly cling to the literal meaning of the source text but focuses on the reproduction of its deep meaning. For instance, in the brief introduction to Guandi Temple in Jingzhou, the phrase “威震华夏” was officially granted by Emperor Tongzhi of the Qing Dynasty. It can be freely translated into "Invincible in China" according to its meaning. This kind of brief translation is proper to be engraved on the inscribed board. Another example is the phrase “乾坤正 气” which was granted by Emperor Yongzheng of the Qing Dynasty. It can be translated into "Unrivaled Integrity" or "Supreme Justice" so as to show the justice of Guan Yu. It is necessary to point out that free translation is not contradictory to keeping the appeal of the original language. Not only transliteration and literal translation but also free translation can create a foreignizing effect. As for target readers, foreigniazation and domestication in translation are a kind of feeling and impression. They are not determined by translation methods but by the difference of language and culture. Only in the difference of source and target language-cultures will foreignization and domestication arise. Even free translation cannot wipe out this otherness. For example, "tithe" and “vingt-et-un” can be freely translated into “什一税” and “二十一点”, which have a foreign flavor because there are no such things in China.

\subsubsection{Substitution of names}

This is a method using today's name to replace the historical one. For instance, in Guandi Temple, “南纪” of “泽安南纪” oin the inscribed board granted by Emperor Qianlong of the Qing Dynasty obviously refers to Jingzhou. “南纪”is the shortened version of “南国之纪” which comes from the Book of Songs. It originally refers to the southern area of China between the Yangtze River and the Han River. Here, Emperor Qianlong of the Qing Dynasty uses “南纪”to refer to Jingzhou. In ancient times, Jingzhou used to be flooded. Emperor Qianlong wrote “泽安南纪”to cordially hope 
that Lord Guan could bless Jingzhou and bring peace to the Jianghan Plain which has frequently been destroyed by floods. It seems that it is improper to retain the old name “南纪” by a transliteration in the target text because even Chinese people today seldom know it. So, it is better to use Jingzhou to replace it. According to its meaning, “泽安南纪” may be translated into “May Lord Guan Bless Jingzhou".

\subsubsection{Imitation}

This is a method using an idiom or a fixed expression in the target language with the same or similar meaning to translate the original text. For example, “败走麦城” and “meet one's Waterloo" have a similar meaning. Thus, we can render “败走麦城” into “Guan Yu met his Waterloo". Another example is “说曹操, 曹操到”. We can refer to the English idiom “Talk of the devil and he will appear" to translate it into "Talk of Cao Cao and he will appear". Imitation is an effective method in tourism translation. When foreign tourists see or hear the translation, they will immediately associate it with the related idiom in their own language and then understand the deep meaning of the source text.

\subsubsection{Amplification}

This is a method which adds words in the target text which do not exist in the surface structure of the source text but whose meaning is contained in its deep structure. For example, we can translate “康熙五十八年”in the brief introduction of Three Visits Hall into “the fifty-eighth year of the reign of Emperor Kangxi", adding "the reign of Emperor" to clearly explain the identity of Kangxi and the meaning of “五十八年”.

\subsubsection{Omission}

This is a method leaving out some words in the original text. For instance, “注意安全，小心滑倒” can be translated into "Wet Floor”, with the first part “注意安全” un-translated because these words are written on the public warning signboard and their meaning is strongly implied by the context.

\subsubsection{Specification}

This is a method which does not render the literal meaning of the source text but convey its specific referent. The examples are “龙凤配” and “鸡公车” in the Three Kingdoms legend in Jingzhou. “龙 凤配” is related to the food-making custom in Jingzhou. It is said that, in order to celebrate the safe returning of Liu Bei and his wife from the Kingdom of $\mathrm{Wu}$, Zhuge Liang put on the table a course called "preserved eggs mixed with tofu which Guan Yu liked very much. Today, in Jingzhou's weddings, this course is sometimes offered on the table. “鸡公车” is related to the production custom in Jingzhou. This kind of vehicle is commonly called monocycle. It is said that it was made by Huang Yueying, Zhuge Liang's wife. It gains its name because it makes the quacking sound when it works. According to their meaning, “龙凤配” and “鸡公车” may be translated into "Preserved Duck Egg Mixed With Bean Curd" and "Cackling Monocycle".

\subsubsection{Transliteration plus free translation}

This is a method which partly imitates the pronunciation of the source text and partly translates its meaning. For instance, in the brief introduction of Guandi Temple in Jingzhou, “刘、关、张桃园结 
义” can be translated into "Liu-Guan-Zhang Alliance".

The former part of the translation uses the Chinese pinyin method, namely, transliteration. The latter part of the translation does not express the surface meaning but the deep meaning, namely, free translation. Another example is the inscription on a tablet of the Changbanpo scenic spot in Dangyang - “长坂雄风” which may be translated into “Changban Heroes”. “雄风” refers to the heroic deeds of Zhao Zilong and Zhang Fei in the Changbanpo Battle. It is easier for foreign tourists to accept this kind of translation.

\subsubsection{Transliteration plus explanation plus literal translation}

This is a method which partly imitates the sound feature of one part of the source text, then explains the transliterated part with the explanation put inside the brackets, and finally translates another part of the source text literally. For example, in Gulongzhong, “躬耕田” can be translated into Gonggeng (Self-plowing) Fields. "Gonggeng” is a transliteration of “躬耕”. "Self-plowing” is the explanation of "Gonggeng" and "fields" is a literal translation of “田”. The translation available of “躬耕田” in the scenic spot translates “耕” into “toil”. This translation seems improper because "toil" cannot collocate with "fields" in logic. It is proper to use "till", "plow (plough)" or "furrow" to render “耕”.

\subsubsection{Elegant translation}

This is a method which adopts dynamic equivalence to achieve formal symmetry or pleasant sound effects in the target text. For example, in Jingzhou, in the publicity billboard of Guanyu Temple, the characters “忠，义，仁，勇” can be translated into “Loyalty, Integrity, Mercy and Bravery”. The four words have the same rhyme /i/. Or they can be translated into "Faithfulness, Justice, Benevolence and Prowess", which has the same ending consonant $/ \mathrm{s} /$.

Besides the translation methods discussed above, there are some other methods, including division, combination, negation, conversion, and so on.

\subsubsection{Translation principles}

Based on the analysis and discussion above, we can draw the conclusions about the principles of cultural tourism translation as follows:

\subsubsection{Faithfulness}

This means that the translated text should not only be faithful to the meaning of the original text, but also to the spread and publicity function of tourism texts.

\subsubsection{Effectiveness}

This means that the translated text should firstly be faithful to the meaning of the original text. However, if this faithfulness cannot effectively convey the meaning of the original text to foreign tourists, we should sacrifice faithfulness and take flexible translation strategies and methods to achieve the translation goal.

\subsubsection{Standardization}

This means that translation strategies and methods for the same source text should remain the same, as in the translation of the names of the scenic spots. Moreover, the printing and engraving of the 
texts as well as the carrier of the texts should also remain the same

\subsubsection{Conciseness}

This means that tourism translation should be as concise as possible and try to avoid redundancy. Use of explanatory notes should be restricted, including interlinear note, foot note, end note, and so on. Two many interlinear notes will often interrupt target readers' reading fluency and make the form of the translated text less neat and beautiful.

\subsection{Other solutions}

The complete solution to the problems in the Three Kingdoms cultural tourism translation in Jingzhou and Xiangyang requires effective measures to be taken. According to the analysis and discussion above, the following suggestions concerning cultural tourism translation are raised.

\subsubsection{Organizing manpower to solve the problems as soon as possible}

From the above analysis it can be seen that translations in China's scenic spots or areas have many problems that require the relevant authorities to take measures to solve them as soon as possible. The scenic area administration or the relevant government department may give full play to various institutions or organizations in translation of tourist resources, such as translators' associations at different levels, professional translators of governmental offices of foreign affairs and local universities, organizing them to carry out the prompt revision of existing translations so as to improve the overall quality of the translation in question.

\subsubsection{Determining which translation should be put on the top agenda}

As for translation blanks, we should deal with them according to priority. The scenic spots have many things to be translated, such as publicity slogans and language materials, public signs, proper names of places and persons, introductions to scenic spots, all kinds of services and tourist souvenirs, travel brochures, and so on. They must be given priority in the translation project. As for the Three Kingdoms culture- related literary works, research literatures, local sceneries, folk tales and folk plays and so on, their translation can be completed by making an midterm or long-term plan, some of which may be finished in five years and some of which may be accomplished in ten or more years.

\subsubsection{Aiming at the international tourism market}

The scenic spots or areas in China should provide not only translations in English but also those in other Asian languages such as Korean, Japanese and Thai. "Romance of the Three Kingdoms", one of the four literary classics in China, is the representative of the Three Kingdoms culture which has an extensive influence in Japan, South Korea, and Southeast Asian countries. The tourists of these countries are now becoming the main part of cultural tourism in China, including the Three Kingdoms tourism.

\subsubsection{Ensuring the translation quality through joint efforts}

The quality of tourism translation is not only related to the translator's work in the linguistic operation itself, but also to the production of the target text in terms of handwriting, printing or engraving. As for the existing translation problems in scenic spots, many of them are not caused by 
the translator, but by the personnel concerned when they have the target text handwritten, printed or engraved on paper, signboards, rocks and so on. Therefore, the relevant government department and the scenic area management department, on the one hand, must be strictly screening translators to develop strict quality control procedures of translating. On the other hand, high-quality work should be ensured to avoid errors in handwriting, printing and engraving.

\subsubsection{Increasing financial input and improving the soft environment of the scenic spots}

Besides the high-quality translation, elegant layout forms of the translation and the accurate handwriting, printing and engraving, the government should be willing to invest in cultural tourism. At present, some scenic spots or areas are not equipped with sufficient facilities. For example, Guandi Temple and Guanyu Temple in Jingzhou do not have publicity slogans in English or in any other foreign language, to say nothing of the translation of the names of the temples and other things of cultural interest.

\section{Conclusion}

Along with the globalization of culture and economy, tourism translation has become an important part in international economic and cultural exchanges. Tourism translation is a kind of important and culturally-loaded creative work. A successful translation of tourism can bring convenience to foreigners who don't know Chinese very well. However, there are a lot of problems in tourism translation. The study of tourism translation from Chinese to English is far from theoretical and instructive. Therefore, the study of the translation of tourism is not only necessary but also urgent.

First of all, the author of this paper introduces the present situation about the translation in the Three Kingdoms cultural attractions in Jingzhou and Xiangyang. Some scenic spots have English translations and some others do not have. The English translations available in the scenic spots have many mistakes in them, including misspelling, misunderstanding of the original text, inaccuracy of translated texts, and so on. Then, according to these problems, she conducts her analysis. Both in Jingzhou and Xiangyang, the translations of the scenic spot introductions are not complete and there is a problem of inconsistency in use of translation methods. In order to solve these problems, she raises some methods, principles and solutions. Though they cannot solve the problems completely, the solutions can be useful in handling them. Finally, the author of this paper wants to present her ideas on the development of the cultural tourism industry in Hubei Province. Jingzhou and Xiangyang are rich in Three Kingdoms culture. This culture is a great treasure of Chinese culture as a whole and every one of us has the responsibility to introduce it to foreign tourists. However, it is not easy to reach this goal. So, not only the translators should try their best in their work, but also the government and every citizen should do what they can to help reach this goal. The Three Kingdoms culture is important not only to the people in Jingzhou and Xiangyang, but also to all the people around the world.

Tourism translation is a practice-based and experience-oriented activity but it still needs theoretical guidance. The existing translation theories have offered the guiding line for tourism translation between Chinese and English which calls for greater efforts to make further studies in the current situation that more and more foreign tourists come to China to visit scenic areas of historical interest. 


\section{References}

[1]Dann, G. The Language of Tourism[M]. UK: CAB International, 1996.

[2]Newmark, P. A Text book of Translation[M]. Shanghai: Shanghai Foreign Language Education Press, 2001.

[3]Nida, E. A. Language, Culture and Translating[M]. Shanghai: Shanghai Foreign Language Education Press, 1993.

[4] Nida, E. A. Linguistics and Ethnology in Translation Problems[A]. In Dell Hymes (ed.), Language in Culture and Society: A Reader in Linguistics and Anthropology[C]. New York: Harper \& Row, 1964:123-146.

[5]Pearce, P. L., Morrison, A. and Rutledge, J. Tourism: Bridges across Continents[M]. Sydney: McGraw Hill, 1998.

[6]Venuti, L. The Translator's Invisibility: A History of Translation (Second Edition)[M]. London and New York: Routledge, 1995/2008.

[7] Chen Gang. Tourism English Translation Course [M]. Shanghai: Shanghai Foreign Language Education Press, 2009.

[8] Chen Gang. Tourism translation and foreign-related tour guide [M]. Beijing: China Foreign Translation and Publishing Company, 2004.

[9] Cheng Jinneng, Lu Hefa.Translational translation theory and practice [M]. Beijing: Tsinghua University Press, 2008.

[10] Ding Dagang. Tourism English language features and translation [M]. Shanghai: Shanghai Jiaotong University Press, 2008.

Journal of Yanshan University (Philosophy and Social Sciences Edition), 2007, (8): 76-78.

[Article in Chinese] Gao M, Gu H, Niu F. On the cultural transmission and loss of tourism translation $[\mathrm{J}]$

[12] He Jizong.Study on the Current Situation and Standardization of Regional Cultural Tourism Translation in Xinjiang [J]. Languages and translations, 2006, (4): 42-45.

[13] Huang Zhonglian. Variable translation theory [M]. Beijing: China Foreign Translation and Publishing Company, 2002.

[14] Jia Wenbo. Tourism translation can not ignore the national aesthetic differences [J]. Shanghai Science and Technology Translation, 2003, (1): 26-29.

[15] Jin-hui Kang. Intercultural tourism translation study [J]. Shanghai Translation, 2007, (1): 34-36.

[16] Jinhui Kang. Cross-cultural tourism translation [M]. Beijing: China Foreign Translation and Publishing Company, 2006.

[17] Jin Huikang.Guangdong tourism translation study [J]. Shanghai Science and Technology Translation, 2003, (2): 23-26.

[18] Lu Hefa, Zhou Jianbo.Translation Translation: Definition, Status and Standard [J] .Shanghai Translation, 2008, (1): 30-33.

[19] "Journal of Ocean University of China (Social Science Edition), 2008, (2): 86-88.

[Article in Chinese] Ma Wenli, Yang Yirong.

[20] Min Dayong, Zhan Yunzhao, Wang Yifang.Study on Tourism Translation [J] .Chinese Translation, 1991, (5): 52-55.

[21] Peng Ping. Practical Tourism English Translation [M]. Beijing: Foreign Trade University Press, 2010. 
[22] Tan Lingping. The Application of the Outstanding Principle Information in Tourism Translation [J] .Bilingual Education, 2007, (12): 45-47.

[23] Tian Hua. "Perspective" in the application of tourism translation [J]. Shanghai Translation, 2011, (3): 67-69.

[24] Wang Ning.Translation quality and image of tourism destination: A review of tourism translation problems [J]. Journal of Chongqing Technology and Business University (Social Science Edition), 2005, (1): 35-38.

[25] Wen Jun, Deng Chun, Gu Tao, Jiang Yujia.Unification of Information and Acceptance: An Investigation and Analysis of Current Tourism Translation [J]. 中国 科技 翻译, 2002, (1): 34-37.

[26] Wu Yun.Characteristics of Tourism Translation [J] .Shanghai Science and Technology Translation, 2004, (4): 61-63.

[27] YANG Hong-ying, HUANG Wen-ying.Research on the Acceptability of Tourism Translation in Chinese and English [J] Foreign Language Teaching, 2009, (4): 68-70.

[28] Yang Jinsong, Zeng Wenxiong. Rhetoric Deviation in Tourism Translation and Its Compliant Aesthetic Fax [J]. Shanghai Translation, 2008, (4): 46-48.

[29] Zeng Lisha.Practice-based Translation Criticism Should Have Theoretical and Objective Argumentability - On "Business Ethics" in Tourism Translation [J] .Shanghai Translation, 2009, (2): 23-26.

Journal of Southwest University for Nationalities (Humanities and Social Sciences), 2009, (5): 89-91. [30] Zheng Lijun.Cultural Tourism Translation Alienation Translation Strategy [J]. Journal of Southwest University for Nationalities, 2009, (5): 89-91.

[31] ZHANG Yan-ge.Chinese-English Tourism Translation Strategy under the Variation Translation Theory [J]. Zhongzhou Academic Journal, 2007, (5): 67-69. 